\title{
Risperidone for schizophrenia
}

\author{
Encouraging results awaiting further research
}

Risperidone is a benzisoxazole derivative that was heralded as a major breakthrough in the treatment of schizophrenia on its British launch last year. To what extent does research published in peer reviewed journals support this claim?

How antipsychotic drugs work is not fully understood. Although their ability to block dopamine receptors is important, a substantial proportion of patients respond poorly to neuroleptics-especially those with "negative symptoms" such as apathy and social withdrawal-so there must be more to the pharmacotherapy of schizophrenia than just an effect on dopaminergic transmission. Other neurotransmitters-for example, 5-hydroxytryptamine possibly acting at $5 \mathrm{HT}_{2}$ receptors, could be involved: in support of this are the antipsychotic properties of clozapine, which has a greater affinity for $5 \mathrm{HT}_{2}$ receptors than dopamine 2 receptors, and the apparent beneficial effect of add on treatment with the potent $5 \mathrm{HT}_{2}$ receptor blocker ritanserin. ${ }^{1}$

Risperidone blocks catecholamine receptors (mainly dopamine 2 and $\alpha 1$ and $\alpha 2$ adrenoceptors) and $5 \mathrm{HT}_{2}$ receptors. It has antihistamine $(\mathrm{H} 1)$ activity but no effect on $\beta$ adrenoceptors, muscarinic cholinoceptors, or peptidergic receptors. $^{2-5}$ Open studies have suggested that it has a therapeutic effect on both positive and negative symptoms of schizophrenia and may be helpful in patients who have not responded to conventional neuroleptics. With lower doses extrapyramidal symptoms do not commonly occur. The results of controlled trials ${ }^{6-12}$ have supported these preliminary observations, and the possibility that risperidone ${ }^{2}$ has a beneficial effect on negative symptoms while at the same time causes fewer extrapyramidal effects has excited interest. As none of the older neuroleptics are as effective or free from unwanted effects as we would like, risperidone is a welcome addition to the pharmacological armamentarium.

Observations published to date have been encouraging, but the results of larger scale studies are needed to ensure that the findings have not been unduly influenced by the many variables known to affect the interpretation of trials. These include selection bias in the types of patients studied, carryover effects of previous treatment, concomitant drug treatment, dose equivalents, numbers of drop outs, and, in the case of multicentre studies, interrater reliability.

On the basis of what is known, risperidone may benefit schizophrenic patients with severe negative symptoms who have not responded to conventional neuroleptics and those with distressing drug induced extrapyramidal symptoms, including dyskinesia, which cannot be controlled by adjust- ment of the dose of neuroleptic or the administration of agents used to treat movement disorders. Risperidone may also help some patients with schizophrenia resistant to treatment and therefore be an alternative to clozapine. Doctors use the term treatment resistance differently; in this context the label should be applied only when a patient has failed to respond satisfactorily to at least two different types of conventional neuroleptics (for example, a phenothiazine and a butyrophenone), given in adequate doses alongside his or her nonpharmacological treatment for an adequate time.

To help prevent postural hypotension risperidone should be prescribed in a low starting dose ( $1 \mathrm{mg}$ twice daily), and then increased gradually (by increments of $2 \mathrm{mg}$ a day) until the recommended dose range of $4-8 \mathrm{mg}$ a day is reached. As is the case with many drugs, postural hypotension can be a particular problem in elderly patients-a starting dose of $0.5 \mathrm{mg}$ twice daily should be used in these patients and in those with impaired hepatic or renal function; thereafter the dose should be increased by daily increments of $1 \mathrm{mg}$ until a dose of 1-2 mg twice daily is reached.

Although existing data are reassuring, risperidone's side effects have not yet been fully defined. The risks are those of any new drug and are likely to be fully revealed only by more research and further clinical exposure. Possiblëeffects related to the drug include anxiety, insomnia, headache, fatigue, impaired concentration, somnolence, dizziness, blurred vision, gastrointestinal symptoms, and weight gain. Some of these symptoms are frequently encountered in schizophrenic patients and are therefore difficult to relate to treatment. ${ }^{13}$

Serious blood dyscrasias, such as agranulocytosis, which is such a problem with clozapine, have not been reported. Higher doses of risperidone (16 $\mathrm{mg}$ a day) cause extrapyramidal effects with a similar frequency to that reported during treatment with haloperidol $20 \mathrm{mg}$ a day-hence the recommended optimum dose of $4-8 \mathrm{mg}$ a day. Like other dopamine antagonists, risperidone increases plasma prolactin concentrations-on average by $100 \%$ in women and $50 \%$ in men $^{7}$-and this may be associated with galactorrhoea, gynaecomastia, menstrual disturbance, and sexual dysfunction.

Little information is available on the drug's cognitive, psychomotor, and epileptogenic effects; cardiac and other effects in overdose; and drug interactions, although its sedative and hypotensive effects may summate with those of other drugs, and risperidone may antagonise the action of dopamine agonists, such as levodopa. As with all new drugs, 
little is known about long term effects or its effects on fetuses and newborn infants (including those effects transmitted through breast milk).

Ensuring compliance with treatment-which is better when drugs are given by long acting intramuscular injections -may be more important than relatively small differences in therapeutic or unwanted effects, and a possible disadvantage of risperidone is the lack of a depot preparation. In the case of new drugs whose profile of unwanted effects has not been fully defined, however, administration by depot injection could lead to serious consequences.

Finally, there is the issue of cost. Twenty eight days' treatment with risperidone $6 \mathrm{mg}$ a day costs $£ 109$ compared with $£ 10$ for the same period of treatment with haloperidol $10 \mathrm{mg}$ a day. At first sight risperidone may not seem a good buy, but a cost-benefit analysis should take into account not only relative drug costs but also differential response rates; untoward effects; patients' satisfaction with treatment and their quality of life; the variable needs for inpatient care, follow up, monitoring of treatment, and involvement of other providers of care; patients' productivity, loss of earnings, and other expenses; and the effect of the illness on families and the community.

A comparative analysis of all of these has not been carried out, although a Canadian study showed that the average number of days (85) spent in hospital during the year that patients received risperidone was less than that (106) during the preceding year, when patients received older antipsychotic drugs. ${ }^{14}$ Although of interest, the results of a retrospective comparison involving only a small number of patients in one country with possibly different criteria for admission than elsewhere may not be generalisable to other countries. One explanation for the apparent benefit from risperidone could have been the extra attention that the patients received while in the research study.
The results of research published to date show hope but until more research (including full cost-benefit analyses) has been carried out doctors and purchasers of health care will have to decide on the basis of their experience and ethics whether the benefits justify the cost.

J GUY EDWARDS

Honorary clinical senior lecturer

University Department of Psychiatry,

Royal South Hants Hospital,

Southampton SO9 4PE

1 Duinkerke SJ, Botter PA Jansen AAI, Van Dongen PAM, Van Haaften AJ, Boom AJ, et al Ritanserin, a selective 5-HT2/C antagonist, and negative symptoms in schizophrenia. A Ritanserin, a selective 5-HT2/IC antagonist, and negative symp
placebo-controlled double-blind trial. Br $\mathcal{Y}$ Psychiatry 1993;163:451-5.

2 Janssen PAJ, Niemegeers CJE, Awouters F, Schellekens KHL, Megens AAHP, Meert TF Pharmacology of risperidone ( $R$ 64 766), a new antipsychotic with serotonin-S2 and dopamineD2 antagonistic properties. ₹ Pharmacol Exp Ther 1988;244:685-93.

3 Leysen JE, Gommeren W, Eens A, de Charroy de Courcelles D, Stoof JC, Janssen PA Biochemical profile of risperidone, a new antipsychotic. 9 Pharmacol Exp Ther 1988;247:661-70.

4 Leysen JE, Janssen PMF, Gommeren W, Wynants J, Pauwels PJ, Janssen PAJ. In vitro and in vivo receptor binding and effects on monoamine turnover in rat brain regions of the novel antipsychotics risperidone and ocaperidone. Molecular Pharmacology 1992;41:494-508.

5 Megens AAHP, Awouters FHL, Schotte A, Meert TF, Dugovic C, Niemegeers CJE, et al. Survey on the pharmacodynamics of the new antipsychotic risperidone. Psychopharmacology 1994;114: 9-23.

6 Borison RL, Pathiraja AP, Diamond BI, Meibach RC. Risperidone: clinical safety and efficacy in schizophrenia. Psychopharmacol Bull 1992;28:213-8.

7 Claus A, Bollen J, De Cuyper H, Eneman M, Malfroid M, Peuskens J, et al. Risperidone versus haloperidol in the treatment of chronic schizophrenic inpatients: a multicentre double-blind comparative study. Acta Psychiatr Scand 1992;85:295-305.

8 Chouinard G, Jones B, Remington G, Bloom D, Addington D, MacEwan GW, et al. A Canadian multicenter placebo-controlled study of fixed doses of risperidone and haloperidol in the treatment of chronic schizophrenic patients. 9 Clin Psychopharmacol 1993;13:25-40.

9 Hoyberg OJ, Fensbo C, Remvig J, Lingjaerde O, Sloth-Nielsen M, Salvesen I. Risperidone versus perphenazine in the treatment of chronic schizophrenic patients with acute exacerbations. Acto Psychiatr Scand 1993;88:395-402.

10 Heinrich K, Klieser E, Lehmann E, Kinzler E, Hruschka H. Risperidone versus clozapine in the treatment of schizophrenic patients with acute symptoms: a double blind, randomised trial. Prog Neuropsychopharmacol Biol Psychiatry 1994;18:129-37.

11 Kane JM. New antipsychotic drugs. A review of their pharmacology and therapeutic potential. Drugs 1993;46:585-93.

12 Livingston MG. Risperidone. Lancet 1994:343:457-60.

13 Edwards JG. The untoward effects of antipsychotic drugs: pathogenesis and management. In: Bradley PB, Hirsch SR, eds. The psychopharmacology and treatment of schizophrenia. Oxford: Oxford University Press, 1986:403-41.

14 Addington DE, Jones B, Bloom D, Chouinard G, Remington G, Albright P. Reduction of hospital days in chronic schizophrenic patients treated with risperidone: a retrospective study. Clinical Therapeutics 1993;15:917-26.

\section{Preventing injuries in childhood}

\section{A new journal for the main cause of childhood mortality and morbidity}

What is the leading cause of death among children and adolescents? Not AIDS, not cancer or diabetes, not cystic fibrosis or heart disease, and certainly not meningitis. For most countries in the developed world, and increasingly in the developing world as well, about one half of all deaths after the first year of life are due to injuries-unintentional and intentional. In Britain in 1990 injuries caused a quarter of deaths in those aged 1-4, more than a third in those aged 5-14, and three of every five deaths in those aged 15-19. Many people - professional and lay-are astonished by these figures.

Despite the frequency, and often serious medical and psychological consequences, of injuries, scientific reports about them are not often found in medical journals. Instead, reports are scattered in numerous other publications, many of them non-medical. While this is understandable given the varied disciplines that make important contributions to the control of injury-for example, engineering, road safety, psychology, and law-the failure of medical journals to register the importance of injuries is more difficult to comprehend. Thus a journal is needed that is accessible to doctors and all others interested in the subject. That is why the BMJ Publishing Group will next March be launching Injury Prevention.

Distressing as the number and seriousness of injuries may be, even more regrettable is the widespread failure to appreciate the extent to which most are preventable. Compounding this ignorance is a widespread failure to implement what is known-and much more is known about the causes of most injuries than is generally recognised.

We must acknowledge, however, that many questions remain unanswered. For example, do boys have consistently higher rates of injury than girls simply because of increased exposure to risk? And, if so, is it innate or socially conditioned? The consistent socioeconomic gradients found for most injuries (with poor people suffering many more) are also puzzling, as are national differences in mortality. Even the impressive recent decline in mortality from injuries seen in many Western nations lacks an explanation. Finally, an overriding methodological challenge is to find accurate ways of measuring exposure in a variety of potentially injurious circumstances.

Much more also needs to be learnt about how best to combine public education with regulation and legislation to change behaviours. Similarly, we need to discover how to fit local circumstances to national control strategies and how best to use input from the community. An overriding concern is to ensure that those responsible for implementing scientific knowledge are made fully aware of the results of research. To 